to contract to any extent of which they might be capable, but more especially the adductor ; whereas the case is very different when the internal rectus is divided, the abductor being still opposed by the two obliques.

14, Langham-place, Regent-street, Oct. $1,1840$.

\section{THE OPERATION FOR SQUINTING.}

\section{To the Editor of THE LANCET.}

SrR:-That many different opinions should be entertained as to the best method of performing the operation for strabismus, is what might very naturally be expected; and it is also very natural that each operator should have a peculiar affection for any little invention of his own. I should have remained, as hitherto, a silent spectator of the various claims to superiority in the performance of this simple, beautiful, and truly scientific operation, had the different competitors for public favour been content with the recommendation of their own plans, without decrying, often most unreasonably, as well as unjustly, those of others. Having no invention of my own to bring forward, having seen the operation for strabismus performed in nearly a bundred cases, and having operated myself several times, I have anxiously endeavoured to form an impartial judgment of the merits of the different methods of its performance. As the operation for strabismus is at present rather a novel one, I trust that the results of my experience upon the subject may not prove entirely useless or uninteresting to those gentlemen who may not have had quite so wide a field for observation as myself. There are two things especially to be desired in an operation - that it should be performed, if possible, with celerity and safety; the next thing desirable is, that no unnecessary pain should be inflicted on the patient. It is upon the latter point, more especially, that appeals to the public are most likely to prove successful; and it has, consequently, been the one which has been the most eagerly seized on by many who have written upon the operation for strabismus. The hook for fixing the eye has been invested with terrurs not its own; and its use afterwards described as the infliction of unnecessary pain : the speculum for raising the upper eyelid has been nearly as much abused as the unfortunate hook. That the improper use of either instrument may cause considerable pain I readily admit, but deny that such is the case if employed with proper care and gentleness. We are told by some gentlemen that the hook and speculum are unnecessary; that the finger of an assistant will answer the purpose of the one, whilst the other can be dispensed with entirely; it is true that the upper eyelid can be raised very effectually by the finger of a practised assistant; but by persons in general the lid will be better raised by the speculum. As to the compa. rative pain of the two methods, I have seen them both properly managed; and, on ques. tioning patients as to which gave them less uneasiness, the finger or the speculum, the answer has been generally the latter; the pain caused by the hook has been greatly exaggerated. It would seem that some men delight in raising giants of straw, solely for the satisfaction of easily knocking them down afterwards. It has been asserted, that the eye is forcibly compressed by the hook, and that considerable injury is inficted by the instrument; if the hook be properly made, very slight pressure is sufficient to fix the eye, which has then only to be drawn gently outwards, in the inward squint, without further compression. The hook can certainly, in many cases, be dispensed with; but it is not every one who can so command the muscles of his eye as to be able to keep that organ sufficiently steady without its being properly fixed; and the omission of the use of the hook will, in many instances, not only prolong the opera. tion, but often render the division of the various bands of adhesion incomplete. I believe the employment of the hook will, in a great majority of cases, by facilitating the operation, be the means of saving the p-tient much unnecessary pain. I have seen the operation for strabismus performed in a great number of instances. In the generality of cases the operation has been completed within a minute; but there have been instances where it was necessary to divide several bands of adhesion, which, of course, rendered the proceeding more protracted. The instruments generally used by Mr. C. Guthrie are a sharp-pointed bistoury with a slight curve; a small director slightly grooved upon its concave surface, and suffi. ciently curved to be passed under the muscle with facility; the hook to keep the eye steady, and a small silver speculum. The incision into the conjunctiva is made by in. serting the point of the bistoury opposite the lower side of the tendon of the rectus, and cutting upwards for a quarter or threeeighths of an inch; the curved director is then passed under the muscle, which is divided upwards by the bistoury along its grooved surface. If the patient after the division of the tendon be capable of directing his eye inwards, or if an external squint, outwards, in any degree, the remaining bands of attachment are readily caught up by the director and divided by the knife: this operation should never be considered complete whilst the eye can be turned at all in wards, or when the squint is in the opposite direction outwards ; for wheu all bands of adhesion are fairly divided, the eye usually appears to be fixed motionless in its orbit, with the cornea in its natural position, very nearly in the centre. I have never seen 
a case of strabismus in which it was necessary to divide any other muscles than the external or internal rectus; and cannot help thinking that other muscles have been often cut unnecessarily: it has been said by some persons that the operation leaves the eye in a worse state than the squint for which it was performed, that it becomes disagreeably staring and prominent; in my own cases no such effect has been produced. I have at. tentively watched a great many of those operated upon at the Ophthalmic Hospital; and, although there has been in some few instances a slight degree of increased prominence in the eye, yet it has never amounted to deformity ; in the great majority of cases, however, the operation has been highly gratifying, and, in many instances, no difference was observed between the eye operated upon and the other. With regard to the number of little hooks that have been invented for fishing up the rectus muscle, I cannot see any advantage they possess over the instrument above described, which, by forming at the same time a director for the bistoury, most certainly facilitates the operation. It has been observed in some few cases that, although immediately after the division of the internal rectus, the patient has been incapable of directing bis eye inwards, yet, in a few days, it has again turned towards the inner canthus. Notwithstanding this untoward occurrence, it has been sometimes found that in the course of three or four weeks the eye has again become quite straight; in such a case, it is to be presumed that the return of the squint has been caused by effused lymph unitung the posterior part of the divided muscle to the sclerotic coat; and that the subsequent return of the eye to the straight position has either arisen from elungation of the lymph, or from the slight adhesions having been broken down by the increased action of the external rectus: when such an occurrence happens, the patient should be made to use the muscles of the eye which has been operated upon, by covering the sound one for some little time. A sufficient period of time has now elapsed since the operation for strabismus was first performed in this country, to enable us to form a tolerably correct judgment of its success; when properly and efficiently performed, that is, when no bands of adhesion are left undivided, with but few exceptions, the operation will prove highly satisfactory. I am, Sir, your obedi rnt servant, ROBERT WADE.

68, Dean-street, Soho, Sept. 28, 1840.

\section{INSTRUMENTS FOR THE LAST NEW OPERATION.}

\section{To the Editor of THE LANCET.}

SIR:-The extremely minute circle in which the ingenuity of man is capable of busily exercising itself, has seldom been illustrated more amusingly than in the multi. tudinous inventions of instruments for the cure of squint. Hooks, double and single, and of every variety of curve, scissors with and without hooked blades, straight and crooked, probe-pointed and otherwise, curved knives, and bistouries and forceps of all shapes and springs, have been contrived and earnestly recommended to the profession, with the inventors' names carefully attarhed. The extensive experience of three or four cases has generally sufficed to satisfy each inventor that his peculiar instrument is invaluable, and forthwith a description of it appears in print. Probably, however, before the article has passed through the hands of the compositor, the author-inventor has cut a few more squinters, and finds the honest, plain old forceps and scissors better than any other instruments for his purpose. With patient politeness, Mr. Editor, you continue to present to the profession, through the omnipresent pages of THE LANCET, each blushing debutant with his cherished hook or speculum; and with extreme complacency each successive inventor presents his delicate piece of mechanism to the world. Each contrivance is said to lessen so much the pain of the proceeding, that the doubt now is, whether any annoyance whatever can be caused by the operation; and so much merit is claimed by each inventor, that there can be none left to spare for one Dieffenbach, of Berlin. Should it, however, at some future time, be thought proper to pay any honour to the inventor of the operation, I propose that each surgeon shall tranemit by the penuy post to Dr. Franz (notwithstanding that he has received. the cut superior oblique from the profession), all the useless hooks, specula, and scissors, remaining after all the squinters of Britain have been cured, to be arranged, monumental-wise, in Dr. Franz's yard, and duly ad. vertised as on view by the profession. Thus may the strabismal column, covered with the names of the inventors, remain, when squinting is gone for ever.

Until lately, Mr. Editor, all the cutters in Europe employed a hook to fix the eye, the only matter of dispute being as to the form of the said hook. Latter!y, however, there has arisen a desire to take French leave of the hook, and a sect of anti-hookites seem likely to give much anxiety and pain to the more orthodox strabismic doctors. One gentleman in particular, from Chelsea, who (like the man that published five hundred hand-bills, to inform bis friends that he intended to treat with silent contempt the insults of some enemy,) tells us that he is "too conscious of the comforts of oblivion" to entertain any object in his communication save the benefit of his friend, and who gives force to his declaration by adding his name and residence in full, seems to declare 